\title{
Business simulations: dynamic, computer based case studies for management development.
}

\author{
P. J. Lawrence \\ School of Management Information Systems \\ Deakin University 221 Burwood Hwy Burwood 3125 \\ Australia \\ Tel: +61392446565 \\ Fax: +61392446520 \\ E-mail:pjl@deakin.edu.au
}

\begin{abstract}
Case studies play a major role in management and business education around the world. However, traditional case studies do not allow students to influence outcomes nor do they generally contain sufficient volumes of information to warrant the use of information systems in their analysis. These shortcomings need not be a problem with business simulation games.

This paper describes the structure and use of business simulations in commerce and information systems curricula and discusses their place in educating managers in the importance of information systems in current business practice.
\end{abstract}

Keywords
Business simulation, management training, education, information systems

\section{INTRODUCTION}

\section{Case studies}

One of the major tools employed in business and management education is the case study which supplements the traditional lecture with active participation and practical illustrations of the theories and principles presented. Case studies generally involve group discussion of a past, real-world application of theory including the actions of the decision makers involved and their consequences.

This case study methodology appears to have originated late last century at Harvard Law School but did not take hold in US business education for a further 50 years (Fripp, 1993, p.51). The world wide spread of this approach to management teaching and learning suggests 
that it is generally accepted as making a significant contribution to the educational experience, although this assertion remains largely unsubstantiated.

Case studies do, however, have several shortcomings. In particular, they tend to remain largely instructor centred, there is limited scope for interaction between participants and students have no opportunity to develop relationships with the case's protagonists. In addition, the historical nature of case studies often makes it difficult to appreciate the dynamics and development of the situation under investigation and rarely offers the opportunity to influence events.

\section{Simulations}

An alternative approach which has gained significant popularity more recently is to involve students in a computer-based simulated role playing exercise where they become the protagonists and control the development of the exercise directly through their own reactions and decisions. These business simulation games, as they are often known, offer the practical participation of the case study method without the disadvantages outlined above. Business simulation exercises are far less instructor dominated, they immerse the participants in the exercise and are dynamic and interactive by their very nature. As Keyes, Wells and Edge (1993) have put it,

\section{A [business simulation] game, in a nutshell, is a dynamic, live case which provides not just a snapshot of realistic business problems but includes a moving picture of many interrelated business problems.}

Much work suggests that business simulations are of equal, if not superior, effectiveness to traditional case studies in many situations (Keys and Wolfe, 1988).

This paper seeks to describe how business simulations operate, how they can be incorporated into the business and management curricula and particularly how they can be used to illustrate the varied and vital roles which information systems have come to play in the modern business environment.

\section{BUSINESS SIMULATIONS}

\section{Why simulate?}

Simulations can be used to study the behaviour of systems under circumstances not readily reproducible in the real system for a variety of reasons as described below.

- Costs may be prohibitive, such as the opportunity cost of system down time or simply because various alternative systems under consideration have yet to be built.

- Lack of sufficient control, where the circumstances of interest cannot be readily produced on demand, being primarily external in nature.

- Timeliness may be a problem as it is often desirable to know the long-term implications of a particular course of action now.

- Danger, physical or financial, from experimenting with risky alternative strategies.

This is also true of business simulation games which allow participants to experiment with 
business strategies without significant cost or the danger of financial ruin, in an accelerated time frame and an environment totally under the control of the instructor (within the limitations of the model being employed).

\section{Simulation games}

The idea of simulation games is not new. The ancient game of chess is, after all, a war simulation, albeit substantially abstract in nature. The earliest recorded use of war games as training exercises appears to have occurred in the $19^{\text {th }}$ century with the German Kriegspiel (van Ments, 1983) but it was not until the 1950s that the first broadly used, computer based business simulation, the Top Management Decision Simulation, was developed (Faria and Dickinson, 1994). Since then computerised business simulations have been increasingly used as tools to aid management training. Increased access to computers, over the past 20 years in particular, has lead to a wide variety of such programs being developed and used around the world. A survey of American Assembly of Collegiate Business Schools, conducted in the 1980 s, found that $95 \%$ of respondents used simulations in their courses (Faria, 1987) while a similar survey in the United Kingdom suggested greater than 90\% use there (Burgess, 1991). Australian tertiary institutes also appear to have keenly adopted business simulations as a teaching and training aid (McKenna, 1991).

In addition, Faria found that many large corporations such as IBM, Boeing and AT\&T use business simulation games as part of their in house management development programmes.

These simulations involve participants taking on the roles of senior managers in some form of business organisation and assuming responsibility for making a variety of management decisions and guiding their enterprises' commercial future. Participants' decisions are entered into a primarily computer based simulation model which determines the resulting new state of the organisation and its environment. This enables students to learn experientially through practical application without the risks and expenses associated with a real organisation.

Some simulations concentrate upon single functional areas such as production management (Greenlaw, Hottenstein and Chu, 1991) while others, widely referred to as Total Enterprise Simulations, cover most, if not all, of the major strategic management responsibilities within the organisation (Cotter and Fritzsche, 1991). Typically this will include marketing, finance, production and, increasingly, HRM.

Often these simulations will be industry specific concentrating on, for example, insurance (Lawrence and McDonald, 1995, Fripp, 1994). Others may be more generic, such as Strategy! (Priesmeyer, 1992) which covers a broad spectrum of industries, or non-specific such as the Business Policy Game (Cotter and Fritzsche, 1991) which deals with an unspecified manufacturing and distribution operation. In addition, some games such as the Multinational Management Game (Keys, Wells and Edge, 1994) concentrate on an international rather than domestic scale.

Such simulations are currently used as an adjunct to many university courses, particularly those relating to strategic management, and while they have their limitations they are generally considered to be useful in familiarising participants with various functional areas of the business, demonstrating theoretical material in a practical framework and encouraging the exploration of team building activities (Elgood, 1993, Faria, 1989). 


\section{INFORMATION SYSTEMS}

Increasingly, Management Information Systems (MIS) and Decision Support Systems (DSS) are playing a part in educational business simulators but their role there is not keeping pace with the importance of information management in modern business administration. Information Technology is now so all pervasive in modern business practice that emphasis is very often placed upon computer aided decision making. Many commercially available simulations provide and encourage the development of spreadsheet DSS to improve the reliability of financial and operational decisions (Cotter and Fritzsche, 1991, Priesmeyer, 1992) but they are extremely limited in their scope.

Often, students are supplied with spreadsheet templates to aid budgeting and forecasting but simulation designers tend to concentrate on participants making their decisions based upon fixed, periodic reports designed by the game's author and little emphasis is placed upon managing the huge volumes of data present in real business enterprises.

Information Technology is now, however, not only aiding management practices but often reshaping them and it can be reasonably argued that simulation games need to place greater emphasis upon the development of information management strategies rather than providing all participants with the same prepacked solution which has often been developed by a game designer unfamiliar with the current state of the art in executive information systems.

\section{Realistic information systems}

While it is clearly desirable to have simulation games that more realistically demonstrate the role of modern information technology, the structure of existing simulations does not lend itself well to such considerations.

\section{Simulation design}

In the early days of computerised business gaming the limitations of information technology dictated the overall design of simulations. Computer systems of the time ran in batch mode with no interaction possible between the program and the user at run-time. This meant that all of the data required by the program, such as the decisions made by the participants in a simulation, needed to be available before the program was run. Program output could not be used by the participants to influence the program and hence there was no possibility of the program's users forming part of a feedback loop at run-time.

The implication of all this for business simulations was that the simulation process needed to be broken down into a series of fixed time periods with managers entering decisions at the beginning of a period, before the program was run, and receiving reports at the end of the period. This lead to simulations that were tied to the simulated organisation's accounting cycle allowing decisions to be made only at the beginning of each period. If, for example, the simulation allowed quarterly decisions then the program would be run to simulate the next quarter's business with no opportunity for participants to alter their decisions, or even view their consequences prior to the end of the quarter. The flow chart of Figure 1 illustrates the course of a typical simulation exercise.

The result of this is simulations which severely limit the management experience. Participants cannot afford to test strategies and plan contingencies since they are tied to their decisions for the entire period. This can often be unrealistic. If, for example, companies make 
quarterly decisions including product pricing and one company adopts a price slashing strategy no one is able to respond for three months. In many industries, such as the oil industry, this limitation would be likely to completely alter management strategies.

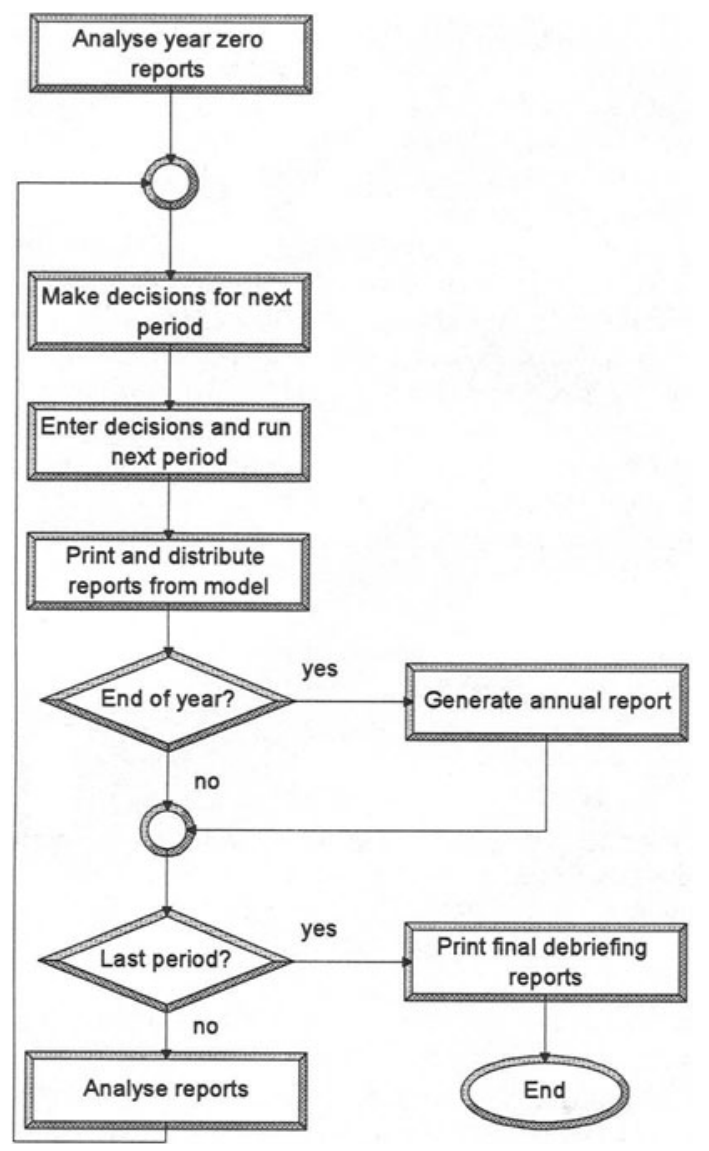

Figure 1 Flow diagram for typical batch mode business simulation.

The batch simulation locks companies into fixed reporting forms and procedures. At the end of the period a predetermined set of reports is delivered to each company. There is no freedom to structure the simulation output in a manner that facilitates the company's chosen decision processes.

In general, such business simulations tend to lock their participants into a particular approach towards decision making which reduces their potential value. The acute lack of 
flexibility discourages creativity which is often a trait which should be emphasised in management training.

Such an architecture also means that the only data available for analysis are period to period macro or aggregate level parameters. No data is provided on the transactional level because batch simulations do not generate it. If, for example, a simulation calculates a marketing company's sales for the quarter then it will use a model which calculates total sales only, rather than generating individual orders and summing them to determine the total.

While the power and availability of computer hardware in universities today (Frand et al., 1987) makes this design obsolete the fact is that it is still the model that persists. There is no evidence in the literature of the existence of a real time interactive business simulation despite persistent calls from users and designers for a new generation of models (Chiesl, 1990, Loveluck, 1989, Teach, 1990, Yeo, 1991).

\section{NEXT GENERATION SIMULATION GAMES}

While business simulation games are widely accepted as a valuable teaching aid it is clear that a new generation of simulations is long overdue - simulations which place greater emphasis upon the role of information technology in the management process. Two examples which go some way to satisfying this need are discussed below. The first, an existing game which has been used in the classroom, is a batch simulation but with a production system which requires the construction of a substantial decision support model for its successful analysis. The second example is a description of a proposed model for an as yet undeveloped real time interactive simulation game.

\section{Dimsim}

Dimsim, the Didactic Industrial Management Simulation (Lawrence, 1995b) is for the most part a fairly typical business simulation of up to 6 medium scale manufacturing companies competing in a closed market to sell three distinct models of their product. The decisions which participants must make are detailed in Table 1. This simulation, however, differs from others in the complexity of the production model employed.

Often simulation games allow participants to change the capacity of their manufacturing facility or to alter the product mix produced. To make this possible there is generally a fairly simple relationship between the size of the plant being operated and its output. As an example, the Business Policy Game (Cotter and Fritzsche, 1991) specifies that hourly production is equal to 1300 units per production line, with a small stochastic variation to enhance realism.

In Dimsim the factory consists of three distinct types of machine which may be purchased in any quantity desired. Each of the three models produced must be processed by some or all of these machines in different sequences. Additionally, the actual processing time for each unit of product on each machine varies randomly with the net effect that there is no simple relationship that can be used to determine production capacity in advance.

This simulation has been used successfully in a course in discrete event simulation where students are required to model their particular production facility in a language such as 
GPSS/H or SIMAN and then use this model to make sensible operational and strategic decisions.

Table 1 Dimsim participants' operational decisions

\begin{tabular}{lll}
\hline Marketing decisions & Financing decisions & Production decisions \\
\hline - selling price of each model & - new bonds to issue or call & - relative production targets \\
- advertising budget for each & - new shares to release to & for each model \\
model & the market & new production staff to \\
- number of new sales reps. & - share dividend to pay for & hire \\
to hire & the quarter & overtime hours in plant \\
- sales reps.' base salary & - surplus cash to be placed & - number of machines of \\
- sales commission & in fixed interest deposits & each type to operate \\
& & $\begin{array}{l}\text { - number of new machines } \\
\text { of each type to purchase }\end{array}$ \\
& & - research and development \\
& & budget \\
\hline
\end{tabular}

\section{A real time model}

The proposed model (Lawrence, 1995b) differs most markedly from batch mode models in that the simulation does not run in discrete, coarse steps generating aggregate data but continuously in pseudo (accelerated) real-time generating transactional data. One week of continuous running may, for example, simulate one quarter's activity.

Participants may interact with the model, entering decisions or requesting market or operational information at any time and as often as desired. Therefore, if a planned strategy seems to be failing after only a month's operation it can be altered before the end of the quarter. What this means is that participants' decision making processes are no longer linked to fixed decision cycles but can be tailored to suit the styles of the managers involved. This increased flexibility should significantly improve the realism of the simulation.

An overview of the model's structure is presented in Figure 2. The heart of this system is a commercial database and the remaining components are specialised modules designed to simulate specific aspects of the companies or their environment.

The system is designed to run on a network based on client-server architecture consistent with current trends in Information Technology. The database resides on a multi-user server to which students have no physical access while client applications running on remote PCs write to and read from the database. The three modules to the left of the database in Figure 2 (Economic Model, Order Generator and Production Model) are all stand alone simulation programs multi-tasking on the same machine as the DBMS and running in accelerated realtime. The five components, to the right of the database, are user interfaces of one form or another and run as clients of the database server whenever users require. They are the users', including the instructor's, only means of interacting with the simulation.

The entire system is coordinated by the scheduler module which performs a function very similar to that of an event scheduler in a traditional discrete event simulation but with simulation time being advanced at a constant rate.

While the operation of each module is dependent upon many or all of the other modules there is no direct communication between them. The Decision Entry modules, for example, 
allow participating managers to enter their decisions which will, in turn affect the Production model. However decision data are not passed directly to the Production model but are stored into the central database. The Production model, which determines the current state of the production lines and generates product, takes the input data it needs from the database.

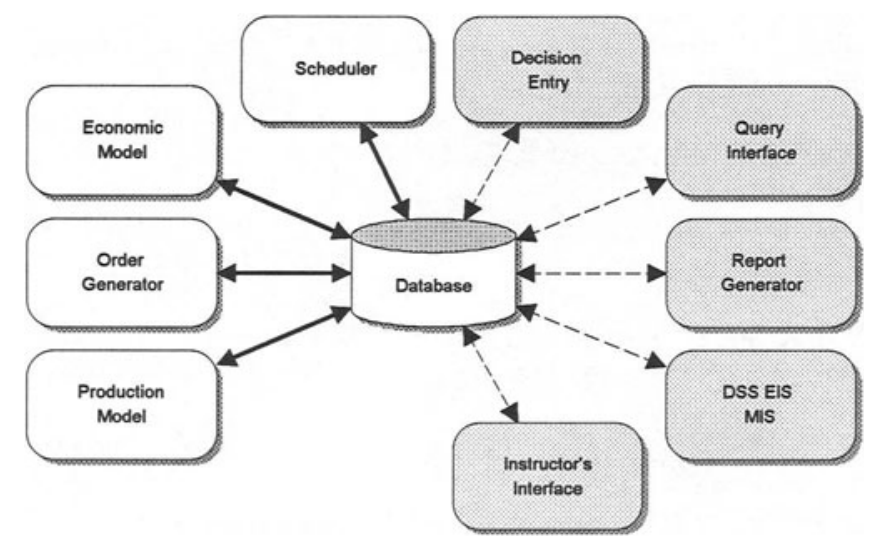

Figure 2 Overall structure of model showing a variety of modules interacting only through the database management system.

The database is structured to hold data for all simulated contingencies and the relevant modules take the data as required. This also makes it possible to tailor the simulation's level of difficulty to the group. The detailed modules that may be used with an MBA group can be replaced with simpler modules for use with undergraduate students.

Use of a commercial database means that participants are not restricted to using the limited MIS and DSS often provided with business simulations. Since all data are stored in a professional DBMS then participants are free to develop their own custom information systems to suit individual management needs using professional application development tools.

\section{CONCLUSION}

Computerised business simulations can be used as an extension of traditional management case studies and can be particularly useful in demonstrating the role of information systems in management to both commerce and information systems students. However, to maximise the advantage of this approach a new generation of more interactive and realistic games is long overdue.

\section{REFERENCES}

Burgess, T. F. (1991) The Use of Computerised Management and Business Simulation in the United Kingdom. Simulation and Games, 22, 174-95. 
Cotter, R. V. and Fritzsche, D.J. (1991) The Business Policy Game. 3rd Ed., Prentice Hall, Englewood Cliffs, USA.

Elgood, C. (1993) Handbook of Management Games. $5^{\text {th }}$ Ed., Gower Press.

Faria, A. J. (1987) A Survey of the Use of Business Games in Academia and in Business. Simulation and Games, 18, 207-24.

Faria, A. J. (1989) Business Gaming: Current Usage Levels. Journal of Management Development, 8, 58-65.

Faria, A.J. and Dickinson, J.R. (1994) Simulation Gaming for Sales Management Training. Journal of Management Development, 13, 47-59.

Fripp, J. (1993) Learning Through Simulations. McGraw-Hill, London.

Fripp, J. (1994) Why Use Business Simulations. Executive Development, 7, 29-32.

Greenlaw, P.S., Hottenstein, M.P. and Chu, Chao-Hsien (1991) PROSIM, A Production Management Simulation. 2nd Ed., Harper Collins, USA.

Keys, J.B., Wells, R. and Edge, A. (1993), International Management Games: Laboratories for Performance-Based Intercultural Learning. Leadership and Organisation Development Journal, 14, 25-30.

Keys, J.B., Wells, R. and Edge, A. (1994) The Multinational Management Game: A Simuworld. Journal of Management Development, 13, 26-37.

Keys, J.B. and Wolfe, J. (1988) Management Education and Development: Current Issues and Emerging Trends. Journal of Management, 14, 205-29.

Lawrence, P.J. and McDonald, T. (1995) The General Insurance Management Instructional Computer Simulation. Proceedings of ASCILITE 1995, Dec. 1995, Melbourne, Australia,

Lawrence, P.J. (1995a) Taking Business Simulations Beyond Batch Mode. Proceedings of the $7^{\text {th }}$ European Simulation Symposium, Oct. 1995, Erlangen, Germany,

Lawrence, P.J. (1995b) The Didactic Industrial Management Simulation. Proceedings of ASCILITE 1995, Dec. 1995, Melbourne, Australia,

McKenna, R. J. (1991) Business Computerised Simulation: the Australian Experience. Simulation and Games, 22, 36-62.

Priesmeyer, H. R. (1992) Strategy! A Business Unit Simulation. 2nd Ed., South-Western Publishing Co., Cincinnati, USA.

van Ments M. (1983) The Effective Use of Role-Play. Kogan Page, London.

\section{BIOGRAPHY}

Peter Lawrence is a Senior Lecturer in the School of Management Information Systems within the Faculty of Management at Deakin University and has previously held research positions with BHP Pty Ltd in Australia, Brown Boveri in Switzerland and has also worked as a business analyst with Credit Suisse First Boston in London. He holds a bachelors degree in engineering and received his Ph.D. in 1985. His teaching and research interests lie mainly in the area of simulation modelling and analysis and he has developed several business simulations for use in courses at Deakin. 